\title{
THE HORIZONTAL FOREARM HARP: ASSYRIA'S NATIONAL INSTRUMENT ${ }^{1}$
}

\author{
By JACK CHENG
}

\begin{abstract}
A horizontal harp, strung with seven to nine strings and usually decorated with a finial in the shape of a human forearm, is likely to have been a symbol of the Neo-Assyrian state. Various features distinguish this musical instrument from contemporary Elamite harps, and from other harps in Mesopotamian history. The horizontal forearm harp was the most frequently depicted musical instrument on Neo-Assyrian palace reliefs and bronze doors; pairs of male Assyrians play the harp for the king in official duties of state or cult. The decorative forearm sometimes wears the rosette bracelet associated with royalty. Consideration of the iconographic significance of the forearm suggests possible Neo-Assyrian attitudes toward music.
\end{abstract}

Austen Henry Layard, the first excavator of the Neo-Assyrian sites of Nimrud and Nineveh, recognized only one musical instrument on all the decorated reliefs he uncovered in Mesopotamia. ${ }^{2}$ In the course of researching representations of music in late Neo-Assyrian images and texts, I found more than two dozen distinct types of instruments, but the most frequently and carefully depicted instrument is the one Layard identified. Although the ancient name of the instrument is currently unknown, I have taken to referring to it as the horizontal forearm harp (Figs. 1-9). ${ }^{3}$ Of course, the frequent depictions do not mean that there were actually more horizontal forearm harps than any other instrument in Assyria; what the frequency of the depiction of this instrument does suggest, however, is its importance to the Neo-Assyrian elite. A description of the horizontal forearm harp, its decoration, players, and contextual uses will all contribute to a greater understanding of the place of this musical instrument in Neo-Assyrian culture, and perhaps offer some insight into other aspects of Neo-Assyrian society.

Before investigating the instrument itself, it is useful to take note of the available sources. During the Neo-Assyrian period (specifically between 883 and 627 B.C.), various kings built palaces for themselves and had the walls faced with bas-relief stone carvings of historical events and iconic images. Large gates were decorated with similar scenes embossed and chased on bronze strips. Select narrative representations depict a number of musical scenes that depict the horizontal forearm harp. Grouped by reign, they are: from Assurnasirpal II's Northwest Palace in Nimrud, Throne Room B, Slab 20 (Fig. 1), Slab 19 (Fig. 2) and Slab 6 (Fig. 3); from the Balawat Gates during Assurnasirpal's reign ASH II L8 (Fig. 4) and ASH II R8 (Fig. 5); from the door of the Temple of Imgur-Enlil in Balawat from Shalmaneser III's reign, Band I (Fig. 6); from Sennacherib's palace at Nineveh, Room III, Slab 8 (Fig. 7) and the Passage to the Ishtar Temple (Fig. 8); and from Assurbanipal's palace at Nineveh, Room S', a single scene displayed on Hunt Slabs D and E (Fig. 9). ${ }^{4}$

\footnotetext{
${ }^{1}$ This article is adapted from my dissertation, "Assyrian Music as Represented and Representations of Assyrian Music" (Ph.D. dissertation, Harvard University, 2001), which concentrates on the period from 883-627 B.C. The material presented has benefited greatly from the advice of Jülide Aker, Andrew C. Cohen, Anne Draffkorn Kilmer, David Roxburgh, John M, Russell and Irene J. Winter. Professor Kilmer was extremely helpful at the earliest stages of my research and I am grateful to her for suggesting the name of the instrument. Dominique Collon read an earlier draft of this article and suggested many helpful amendments. I am indebted to Julie M. Crosson for support of every conceivable kind.

${ }^{2}$ Although he did acknowledge that it was probable that other types existed (Layard 1849: II, 313).
}

\footnotetext{
${ }^{3}$ Previous researchers had suggested that this instrument is actually a dulcimer, a type of zither, based on an early misreading of a bad restoration and from translations of biblical instruments. This has been refuted by a number of scholars and by a new restoration that clearly shows a harp, as discussed by Mitchell (1980).

${ }^{4}$ By museum number, these are, in the same order: BM 124533, BM 124535, BM 124550, BM 124690, BM 124696 , BM 124662, BM Or Dr IV 41, BM 124948+BM Or Dr VI 45, BM 124886 .

Some major bibliographic references for this group as musical representations are Rashid 1984; Rimmer 1969; for primary publications, see Barnett, Bleibtreu and Turner 1998; Barnett 1976; Curtis and Tallis 2008. More detailed bibliography on each scene can be found in Cheng 2001 .
} 


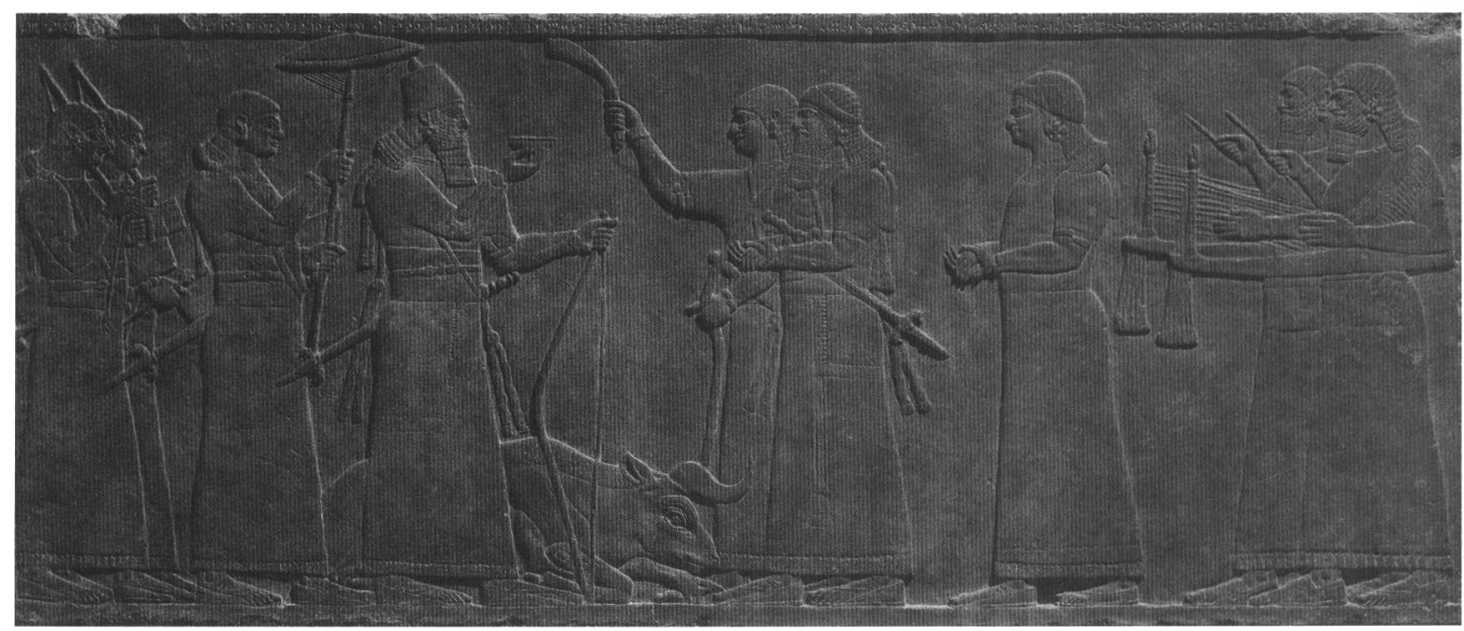

Fig. 1 BM 124533. Nimrud, North-west Palace of Assurnasirpal II, Throne Room B, Slab 20: Libation following a bull hunt. (C) Trustees of the British Museum.

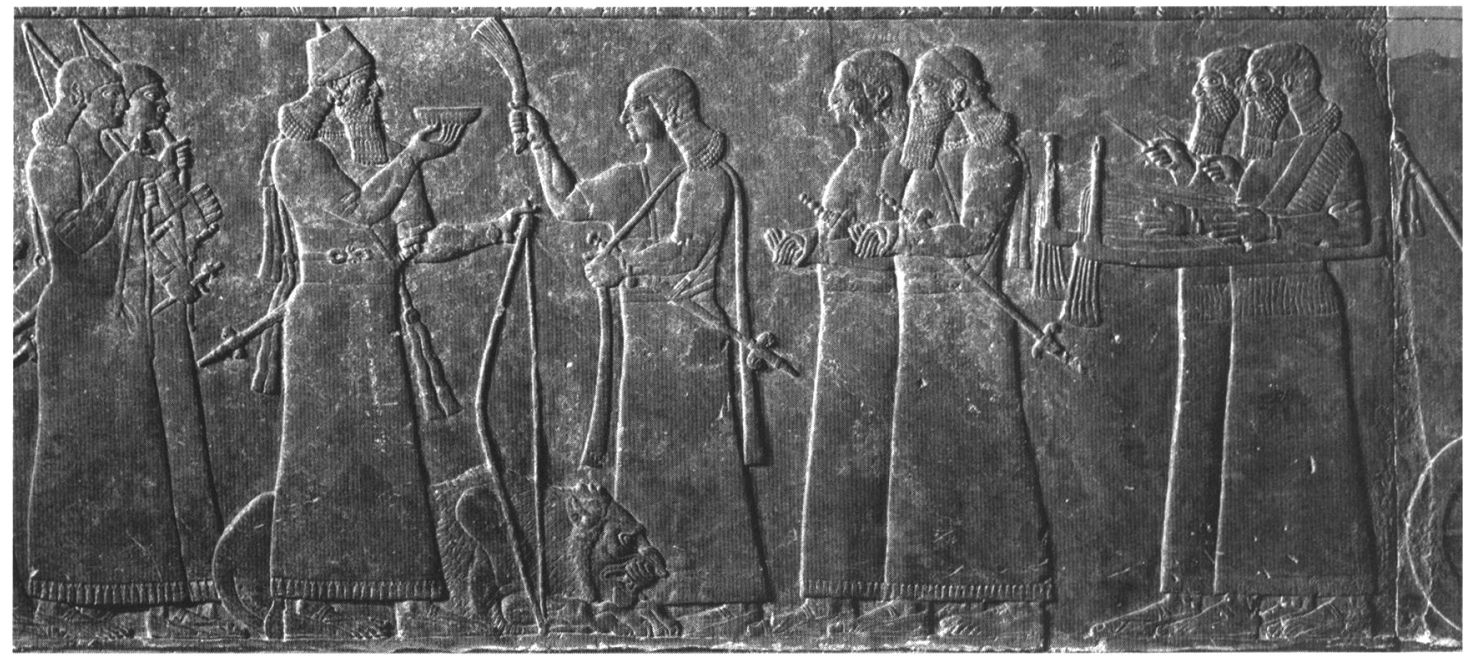

Fig. 2 BM 124535. Nimrud, North-west Palace of Assurnasirpal II, Throne Room B, Slab 19: Libation following a lion hunt. (C) Trustees of the British Museum.

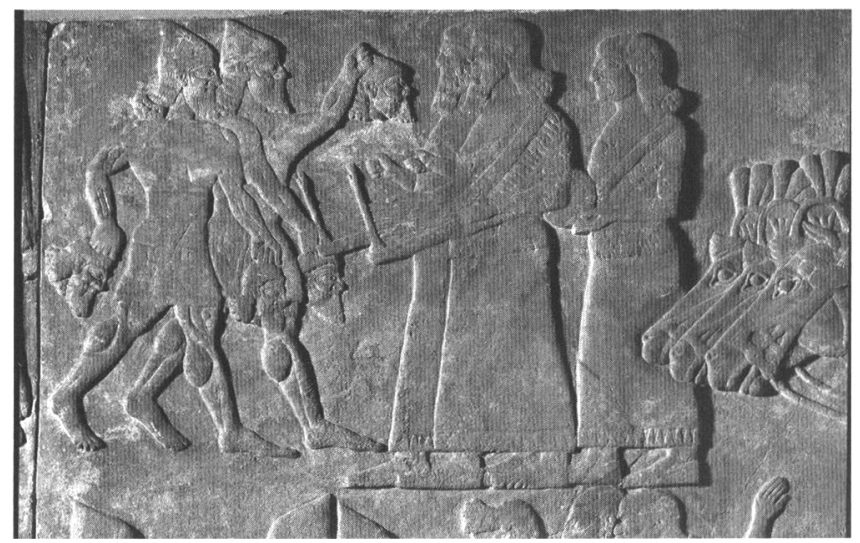

Fig. 3 BM 124550. Nimrud, North-west Palace of Assurnasirpal II, Throne Room B, Slab 6: Musicians accompanying soldiers who hold decapitated heads. $\mathcal{C}$ Trustees of the British Museum. 


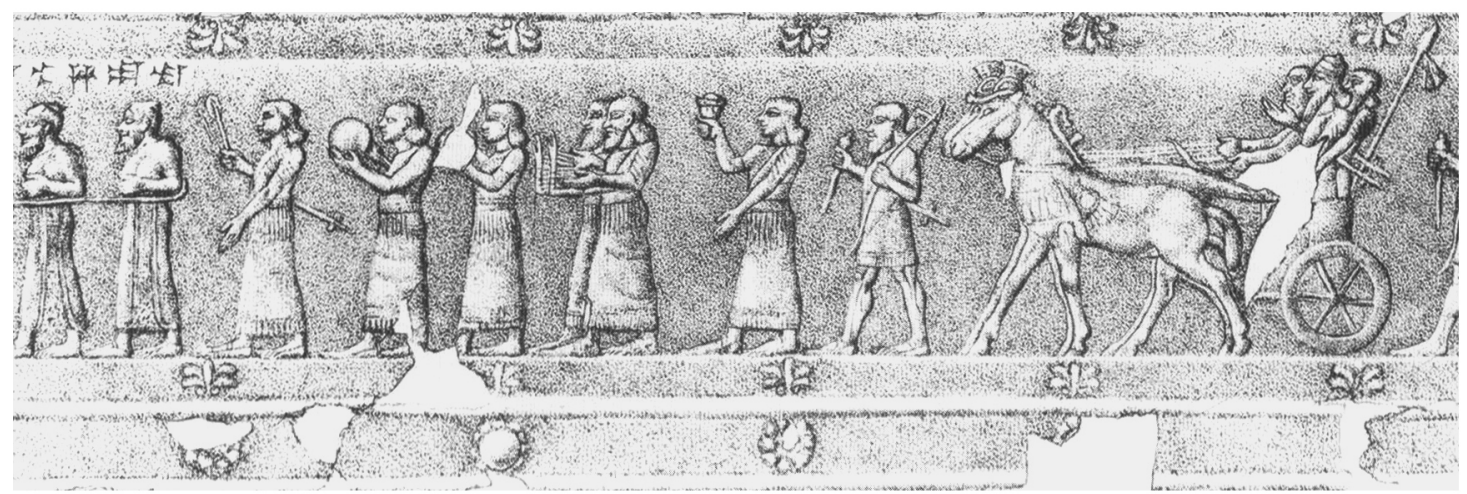

Fig. 4 BM 124690. Balawat, Assurnasirpal II Gates, ASH II L8: King and his entourage lead foreign captives. (C) Trustees of the British Museum. Drawing reproduced by the courtesy of the Trustees of the British Museum, J. E. Curtis and N. Tallis.

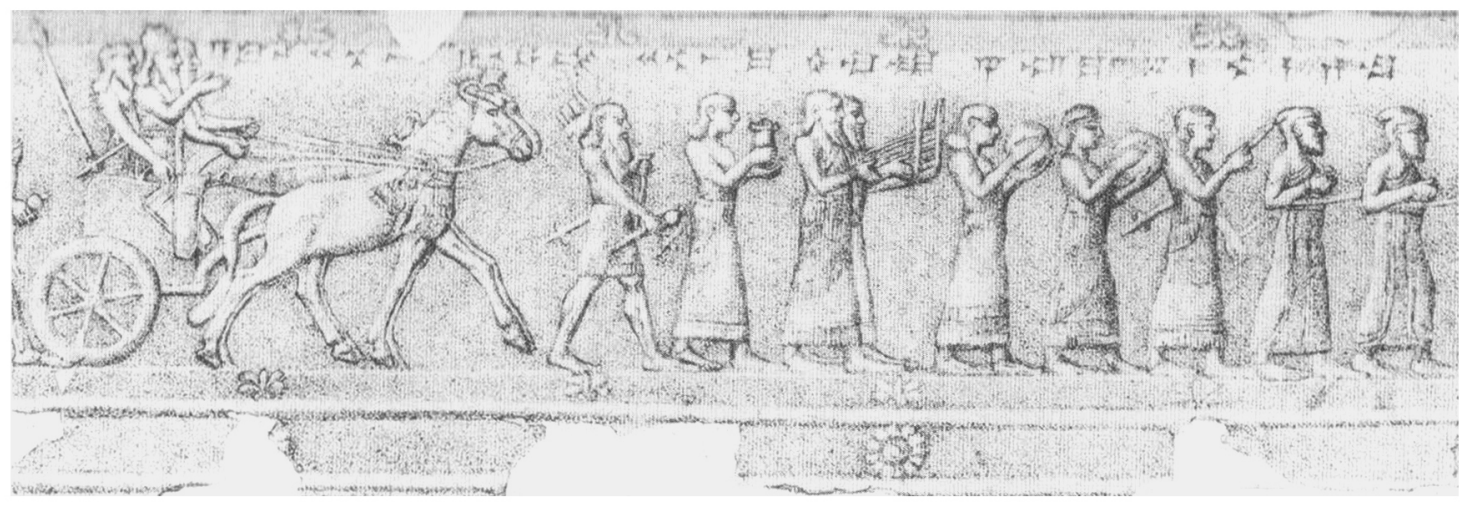

Fig. 5 BM 124696. Balawat, Assurnasirpal II Gates, ASH II R8: King and his entourage lead foreign captives. (C) Trustees of the British Museum. Drawing reproduced by the courtesy of the Trustees of the British Museum, J. E. Curtis and N. Tallis.

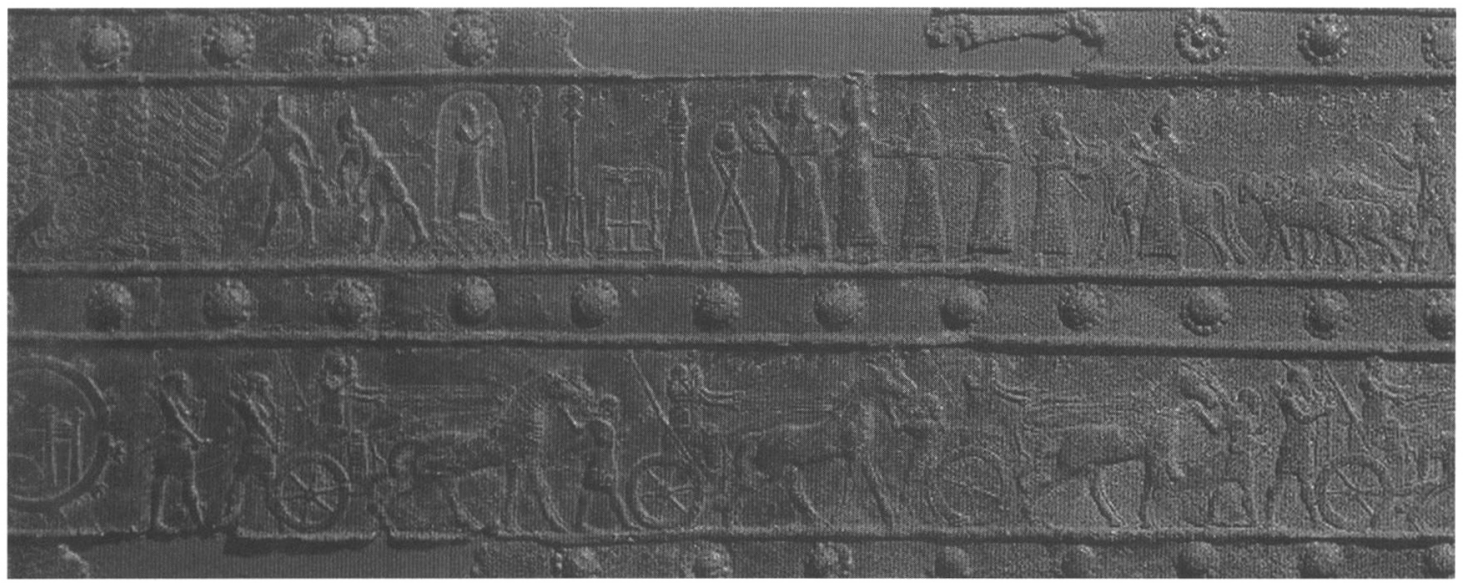

Fig. 6 BM 124662. Balawat, Shalmaneser Gates, Door, Band I: Dedication of a Statue; musicians on the upper register stand behind the offering table. (C) Trustees of the British Museum.

\section{The horizontal forearm harp}

Modern musicologists define a harp as an instrument with two angled arms between which are strung parallel strings. (Lyres are often confused with harps; lyres have an essentially quadrilateral shape, as opposed to the triangular harps.) Horizontal and vertical harps are categorized by the orientation of their strings. The L-shaped frame of the horizontal forearm harp extends horizontally 


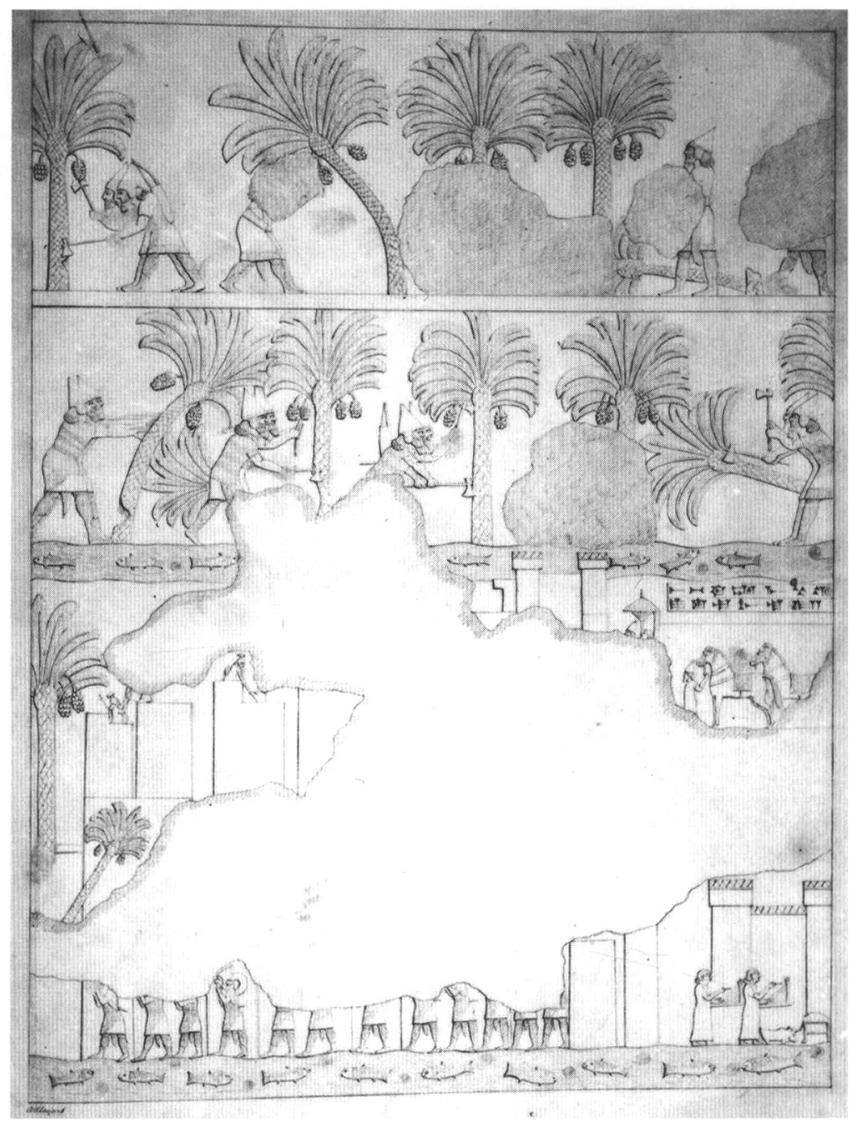

Fig. 7 BM Or Dr IV 41. Nineveh, South-west Palace of Sennacherib, Room III, Slab 8: Sack of Dilbat with two harpists in lower right corner. () Trustees of the British Museum.

from the player's waist and turns up at the far end. The vertical post is topped with a finial shaped like a forearm, complete with a hand, palm open. Strings extend from the horizontal arm near the player to the vertical arm at an acute angle. Where details on representations can be read, this instrument is strung with between seven and nine strings, nine strings in the majority of representations. ${ }^{5}$ Extra lengths of string may dangle from the vertical end of the instrument, sometimes with tassels at the end. The instrument is played by plucking or striking the strings with a plectrum, a long straight stick that functions like a guitar pick. The plectrum is held in the right hand. The left hand is held near the strings, perhaps for dampening, plucking, or bending the strings. To support this instrument, the musician wears a strap over his left shoulder, and holds the frame of the instrument between his left arm and his torso. ${ }^{6}$

Forearm harps are almost invariably played in pairs, and always by male Assyrians. The pairing is emphasized on a series of reliefs in Sennacherib's palace depicting a procession (Fig. 8). Most of the figures in this procession walk in single file, in contrast to two pairs of harp players who overlap

\footnotetext{
${ }^{5}$ Differences occur even among pairs of harps on the same representation, as in Figure 8, where the closer harp on the right has eight strings whereas its matched pair has nine. The two harps on the left, documented only in a drawing, appear to have had nine strings each. This inconsistency suggests the existence of one of two opposing interpretations: either a visual aesthetic that is not based on absolute accuracy or one of extremely detailed description. Given that the inconsistencies themselves are not consistent (that is, an eight-stringed harp is only once paired with a nine-stringed harp), I find the former interpretation, that the visual artist was not exact, more likely.
}

In any case, the range of variation - between seven and nine strings - is narrow enough to be considered accurate within reason. It is equally possible that some strings were originally painted on the stone reliefs, and the paint now lost, so the depictions would have been consistent when the art was fresh.

${ }^{6}$ Holding the instrument on the left side of their bodies is consistent in all the depictions whether the musicians are facing the viewer's right or left. If the left elbow is putting pressure on the frame of the harp, this would limit mobility to some degree and would have a bearing on how the instrument was played. 

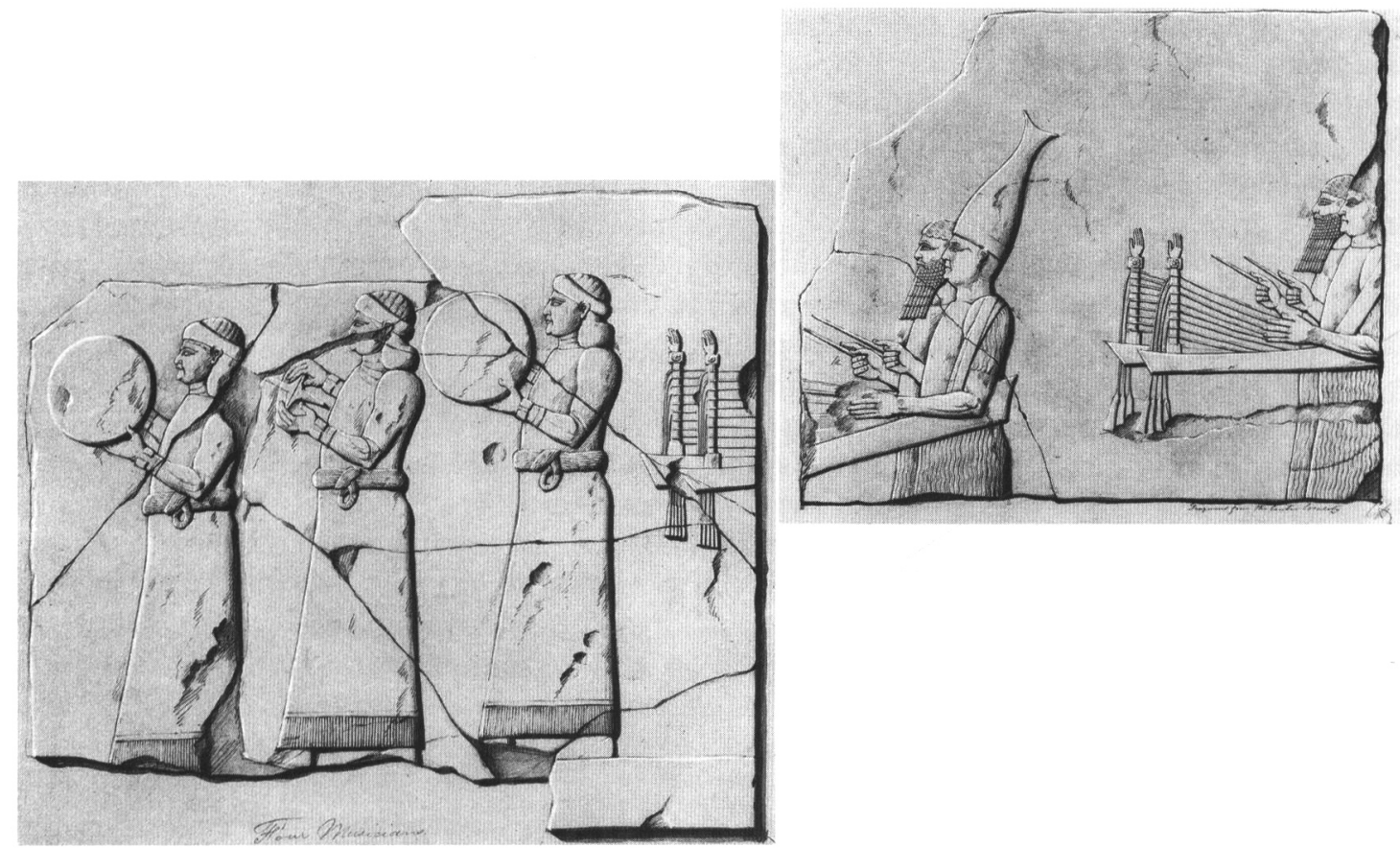

Fig. 8 BM 124948+BM ANE Or Dr VI 45.Nineveh, South-west Palace of Sennacherib, Passage to the Temple of Ishtar: Procession. (C) Trustees of the British Museum.

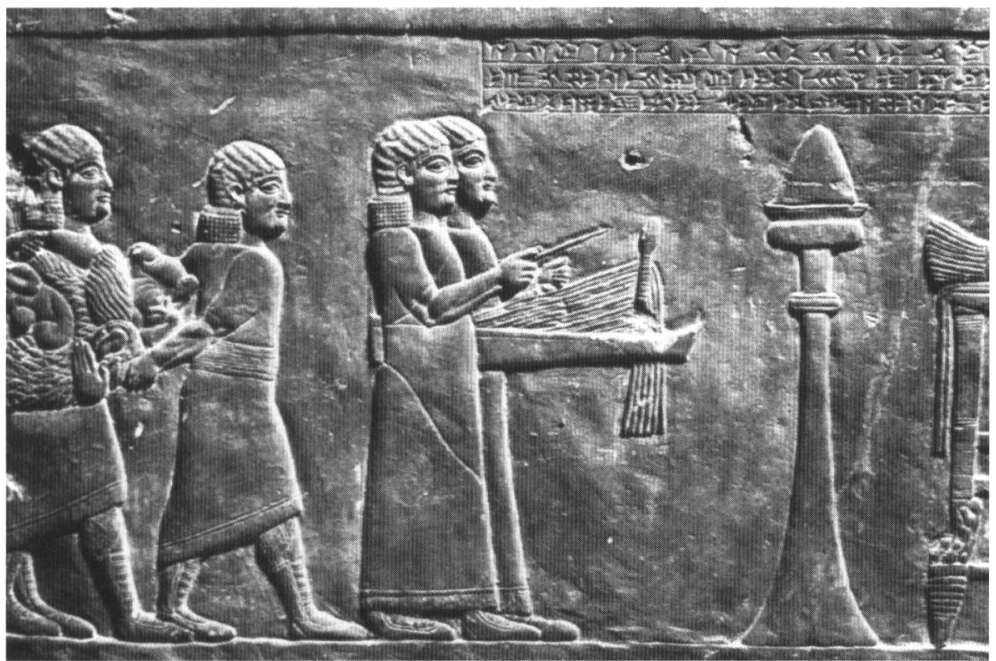

Fig. 9 BM 124886.Nineveh, North Palace of Assurbanipal, Room S', Slab D: Libation after a lion hunt (C) Trustees of the British Museum.

so closely as to appear to be walking shoulder to shoulder. ${ }^{7}$ This pairing is not a convention applied to all musicians - the percussionists that precede the harpists walk in single file. Of the nineteen representations of Assyrian horizontal harps, eighteen are shown in nine pairs, seven of those pairs being tight overlaps, often among single file processions. ${ }^{8}$ In the one instance where a forearm harp

${ }^{7}$ This same overlapping configuration of horizontal forearm harp players is seen on the Balawat Gates from Assurnasirpal II's era, BM 124690 and BM 124696 (Figs. 4 and 5) but not the gates from Shalmaneser III's reign, where the horizontal harp players are shown in single file (Fig. 6).

${ }^{8}$ It may be worth questioning whether the figures in each pair can be distinguished from one another. The short answer is: not usually. From Assurnasirpal II's reign, both harpists are bearded, from Sennacherib we see one bearded musician paired with an unbearded partner followed by a similar mismatched pair in one scene, and two unbearded harpists in another scene, and in Assurbanipal's era two unbearded men are paired together. 
appears alone, on a relief from Assurbanipal's reign, two identical men, tightly overlapping and in the same posture and costume, have only one instrument between them, held by the player closest to the viewer (Fig. 9). When considered together with mistakes in hand positions on the relief, I interpret the single harp player as an anomaly that may have been an oversight rather than a deliberate representation. (The left hand of the harp player is not behind the strings where we would expect it; the right hand of the individual behind him is raised, as if to play his missing instrument. It is possible to suppose that the figure farthest from us may have had his instrument painted on the stone, rather than carved. ${ }^{9}$ ) It seems reasonable to conclude that the forearm harps were meant to be played in pairs. Whether the two instruments doubled up notes, played harmonies or counter melodies in the same or different tunings are questions to raise, but they cannot be answered with the data currently available. Percussion instruments ${ }^{10}$ occasionally accompany the pairs of forearm harps, specifically frame drums and cymbals, and, it has been suggested, sistra. ${ }^{11}$

The horizontal forearm harp is one of just two instruments played exclusively by male musicians in representations. ${ }^{12}$ The other is the trumpet. Similarly, this harp and the trumpet are the only two instruments played solely by Assyrian musicians on the reliefs. ${ }^{13}$ The one known context for trumpet playing, encouraging laborers in quarrying scenes, requires that the supervisor coordinating the labor be Assyrian (and, presumably, male). The restricted use of the forearm harp may also be tied to its function and symbolism.

\section{Other harps on Neo-Assyrian reliefs}

Before discussing the use and significance of the horizontal forearm harp, it is useful to survey some other harp types from this period. Some of these are Assyrian horizontal harps, while another is a foreign horizontal harp. Acknowledging these different types and a brief history of both horizontal and vertical harps in Mesopotamia will help to define the horizontal forearm harp for further analysis.

I have grouped some horizontal harps into the corpus of forearm harps even though they do not have the distinctive forearm finial. Having established how and where the horizontal forearm harp is shown being played, I will now argue that the three horizontal harps, pictured in two scenes, that do not have the eponymous forearm finial are still plainly Assyrian and are rightly included as such here.

An Assyrian horizontal harp without the forearm finial appears on a relief from Throne Room B in Assurnasirpal II's palace (Fig. 2). In this libation over a dead lion, a musician with a horizontal forearm harp is paired with a musician whose harp ends in a knob. The overlapping, paired, and

\footnotetext{
${ }^{9}$ Something similar occurs where two forearm harp players overlap on reliefs from Assurnasirpal II's reign. On BM 124533 and BM 124535 (Figs. 1 and 2), Assurnasirpal II offers a libation over a dead bull and a dead lion and two musicians play harps to the right of each scene, facing left. The different planes of depth are shown in an unexpected order. First is the closer player's left arm, as we would expect, and then another left arm (presumably that of the player behind), the strings of the first instrument, the right hand of the first player, and then the strings of the second instrument and the right hand of the second player follow. The order of limbs may indicate that it was possible to see through the strings. This may be a visual convention that differs from our own, or this may be another occasion to remind ourselves that the work that remains is incomplete. If the final work of art was painted, it is conceivable that the strings may have been painted over the hands that were carved in relief. This would be an effective way to portray the two dimensional string over the rounded forms of the figure.

Generations later, on BM 124920, Assurbanipal's "Banquet" scene, the artist(s) successfully renders a hand behind a veil of strings using only relief carving.

Dominique Collon (pers, comm.) suggests that the absence of strings across the players' hands is the same convention that prevents bow strings from crossing an archer's face and
}

that by the time of Assurbanipal, these artistic conventions were no longer so rigidly applied.

${ }^{10}$ In some instances, the percussion precedes the forearm harp, as on the series BM 124948 + BM Or Dr VI 45 (Fig. 8), and on the bronze doors BM 124662 (Fig. 6). These scenes depict processions, which Figure 3, with a frame drum behind the forearm harps, does not. One might expect a regular ordering of instruments in processions and on representations, but this small group, with three of four examples showing some similarity, is the only indication of some consistency of order.

${ }^{11}$ Sistra are tentatively identified as such in the official publication of Assurnasirpal II's bronze reliefs, Curtis and Tallis 2008 , but the images are worn and hard to read. It would be prudent to leave the identification of sistra as a possibility rather than as a likelihood.

${ }_{12}$ Although some have suggested different social roles for bearded and unbearded men, both play this instrument and are even paired together, as on Figure 8.

${ }^{13}$ The trumpet is only known from three depictions in one sequence in Sennacherib's South-west Palace, Court VI: slab 53 , slabs 54 and 56 , and slabs $63-4$. This narrative is essentially one context, so the sample size is small. Recognizing the trumpet's exclusive use by Assyrian men then, should be taken as observational fact and not considered a general conclusive rule. 
identically attired male Assyrian musicians suggest that this knobbed harp is there in place of a forearm harp but otherwise treated the same. An adjacent, parallel scene from the same room depicting a nearly identical libation over a dead bull (Fig. 1) shows two harps, both with the forearm finial. Although I can offer no credible explanation for the knob in place of a forearm in the lion libation scene, I will note that the first evidence of the horizontal forearm harp is dated to Assurnasirpal II's reign; perhaps this knobbed example represents a transition to a NeoAssyrian form.

Two more Assyrian horizontal harps without the forearm finial are shown on the Balawat Gates dating from the reign of Shalmaneser III (Fig. 6). The bronze door reliefs are considerably smaller in scale, and thus the finial may have been eliminated as an abbreviation of the visual artist. That said, bronze gates from Balawat made during Assurnasirpal II's reign do show a finial; the decoration on the instrument is not detailed, but a split at the top can be clearly read as the fingers and thumb of a hand (Figs. 4 and 5). ${ }^{14}$ The Shalmaneser-era instruments are played in pairs by male Assyrian musicians, as we have come to expect with the forearm harps.

The identification of these anomalous Assyrian harps without forearms is important because there is another horizontal harp depicted in this period that should be distinguished from the Assyrian forearm harp. A brief description of this Elamite instrument will help to define the Assyrian form more clearly and correct some misunderstandings in the scholarly record. This horizontal harp is played by an Elamite prisoner on a relief from the South-west Palace at Nineveh, attributed to the reign of Assurbanipal (Fig. 10). The instrument is about the same size as the forearm harp but shaped differently - the bottom of the harp is rounded like a boat bottom-and decorated differently - there is no forearm on the vertical post and the horizontal length is decorated with dotcentered circles. ${ }^{15}$ This instrument is strung with ten strings. The rounded bottom, the circles, the number of strings and the distinctively knotted tassels all differentiate the Elamite instrument from Assyrian harps, even before taking into consideration the lack of a forearm finial.

The relief shown in Figure 10 was originally reconstructed incorrectly, but the erroneous plaster has since been removed and the carving restored to a broken state by the British Museum. This change is the subject of T. C. Mitchell's article, "An Assyrian Stringed Instrument". ${ }^{16}$ Mitchell's hypothetical reconstructed instrument imagines the vertical forearm element that was lost due to a chance break in the relief. A vertical post undoubtedly existed for the instrument to have made any logical sense, but the decorative forearm finial on Mitchell's reconstruction of that post is not

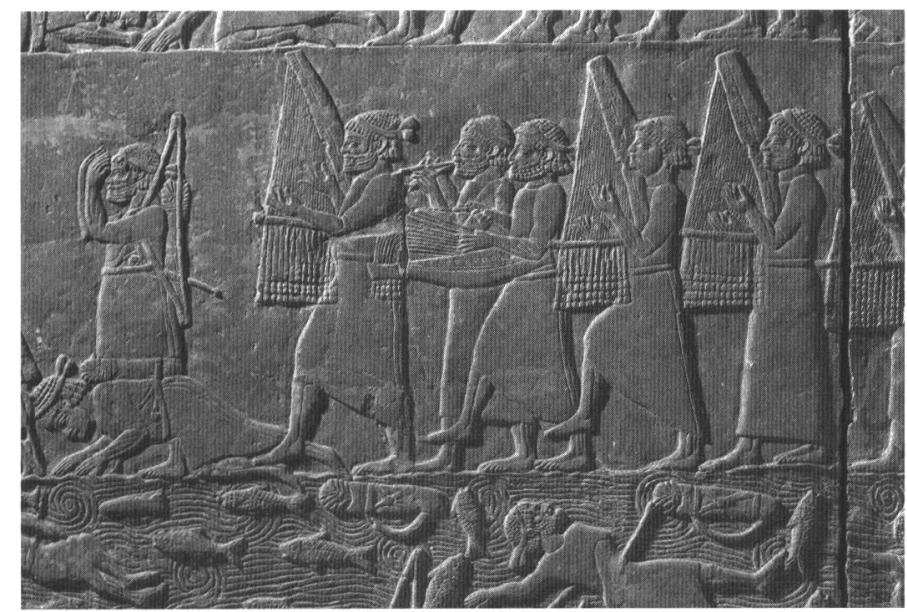

Fig. 10 BM 124802. Nineveh, South-west Palace, Room XXXIII, Slabs 5-6 (carved in the reign of Assurbanipal): Elamite prisoners with vertical harps and a single horizontal harp. (C) Trustees of the British Museum.

\footnotetext{
${ }^{14}$ The drawings by Marjorie Howard help to clarify these details (Curtis and Tallis 2008: 37, 45, figs. 22, 38).
}

\footnotetext{
${ }^{15}$ Lawergren and Gurney (1987) suggest these circles may represent sound holes.

${ }^{16}$ Mitchell 1980.
} 
certain. In fact, based on the slightly different shape and decoration of the instrument, the nonAssyrian player and the composition of the musical group-a single horizontal harp among many other string and wind instruments-I would argue that the forearm finial should not have been reconstructed. After all, this is not truly "An Assyrian Stringed Instrument", but rather an Assyrian representation of an Elamite stringed instrument. As further evidence, Neo-Elamite reliefs at Kul-e Farah have representations of horizontal harps without the forearm on the vertical post. ${ }^{17}$ The relevant reliefs are Kul-e Farah I and IV and are dated to the end of the 7 th century B.C. and the 9th century B.C. respectively; in other words, they are native depictions of Elamite musical culture contemporary with the Neo-Assyrian reliefs. With the limited evidence available, one cannot know whether some of the morphological differences between the Elamite and Assyrian horizontal harps were merely cosmetic or whether there was an acoustic difference between the two. One thing is certain: the Elamite harp-in both Assyrian and Elamite depictions--is shown to have been played singly, unlike the paired Assyrian horizontal forearm harps; thus, unless the Assyrian harps were played in strict unison, the styles of music produced by these techniques would have been different. ${ }^{18}$

\section{Harps in Mesopotamia}

Harps of vertical and horizontal orientations have a long history in Mesopotamia and neighbouring cultures. Vertical harps (Fig. 10) have a more easily traceable visual ancestry, from Old Babylonian clay plaques through the incised decoration of a Middle Assyrian comb. ${ }^{19}$ Although tuning and playing conventions may have changed in Neo-Assyrian times, the vertical harp seems to have developed from local Mesopotamian traditions.

A type of horizontal harp was among the instruments found in the Early Dynastic Royal Cemetery of $\mathrm{Ur}$, and its wooden frame reconstructed from impressions in the soil and the surviving decorative elements of metal and stone. ${ }^{20}$ Based on the shape of the instrument and the angle of the strings, however, this Early Dynastic instrument does not seem to be a direct precursor of the portable Assyrian horizontal harps. As far as we know, the horizontal forearm harps are first depicted in the first millennium B.C., with no evidence of similarly decorated instruments from before the NeoAssyrian period. ${ }^{21}$

The late introduction of the instrument in Mesopotamia, coinciding with the rise of the Neo-Assyrian state, leads one to wonder if the forearm harp might be a foreign import, possibly from the West Semitic groups who influenced other aspects of Assyrian culture, like the carved palace reliefs themselves. ${ }^{22}$ Such a suggestion does not seem to fit, however, with the use of the instrument at the centre of Assyrian cultural practices, as I will demonstrate. Perhaps then, this was a native instrument given new prominence in this period. In either case, whether of local or foreign origin, the horizontal forearm harp was strongly associated with the Neo-Assyrian state in ways that other instruments were not.

The functions of the two Iron Age types of harp in Assyria are decidedly different. Whereas the vertical harp is shown at banquets (including foreign banquets interrupted by the Assyrian army), the horizontal forearm harp is shown in military and religious contexts. The military contexts include the dedication of a border monument (Fig. 5) and the aftermath of battles (Figs. 3, 4 and 7), and the

\footnotetext{
${ }^{17}$ These reliefs are discussed and reproduced in drawings and photographs in de Waele 1989.

${ }_{18}$ The pair of harps from Assurnasirpal II's Throne Room B, one with a hand and one ending with a knob (Fig. 2), seem to visually suggest that the two instruments are playing different parts.

${ }^{19}$ Old Babylonian plaques with harps include IM 55863, V 456 from the Iraq Museum (Rashid 1984: 106-7, figs. 114 15). Lawergren points out that the Middle Assyrian comb from Tomb 45 in Ashur (VA Ass 1097) shows the harp being carried on the right side of the musician, rather than the left as on Neo-Assyrian images (Harper et al. 1995: cat. 46, pp. $85-86$, fig. 21 , h. 6 ).

${ }^{20} \mathrm{BM} 121198$ was first incorrectly reconstructed as one instrument from the remains of two instruments, a bull
}

headed lyre and a round silver harp (Barnett 1969: 98-100; pls. $12 \mathrm{c}$ and $\mathrm{d}$ reproduce the amalgamated reconstruction and Woolley's notebook sketch, pl.17b, is a drawing of the proposed harp on its own).

${ }^{21}$ The closest precedent would be a horizontal harp depicted on an Old Babylonian plaque from Tell Asmar, now in the Louvre (AO 12455; illustrated in Parrot 1961: fig. 378). Differences between this instrument and the NeoAssyrian horizontal harp include the number (seven) and length (shorter) of strings, and the inclusion of a sounding box. As played, the Old Babylonian harp was pinned between the left arm and body, without a strap.

${ }^{22}$ On (non-musical) cultural influences on Assyria, see Tadmor 1975; Winter 1982; Lamprichs 1995. 
religious scenes include libations (Figs. 1,2 and 9), processions to a temple (Fig. 8), and the dedication of an image of the king (Fig. 6). The common denominator between these two categories of events is the presence of the king, as leader of the Assyrian army or as officiant in the religious cult of Ashur. In all known depictions of the horizontal forearm harp, the king is present. ${ }^{23}$ The vertical harp, with a longer known history in Mesopotamian art, is shown to have been played at informal events (like Assurbanipal's banquet) while the horizontal forearm harp, with a lifespan that matches the Neo-Assyrian period, appears in more ceremonial contexts.

To summarize so far, the horizontal forearm harp was depicted more than any other instrument, was only played by Assyrian men and was almost always played in pairs. The pairing of the horizontal forearm harps in representations is the most consistent musical combination of Neo-Assyrian instruments (other groupings are found only once). The instrument is first depicted in the first millennium в.C. and is shown in representations of military and religious settings.

\section{The iconography and significance of the horizontal forearm harp}

All of the horizontal forearm harp's observed associations point to a close relationship with the king. This in turn requires a consideration of the various roles the king played and how these royal functions might affect how the harp was read as an iconographic element in the larger scene.

The eponymous vertical finial of the horizontal forearm harp depicts a human forearm and hand, and in one case, from the Passage to the Temple of Ishtar in Sennacherib's Palace (BM 124948, Fig. 8), four examples are shown with rosette decorations around the wrists. Although the rosette wristband is unique to these four instruments, the symbolism is significant. The only other arms that wear a rosette wristband belong to the Assyrian kings and the protective genii that surround them in images. ${ }^{24}$ One would not expect the rosette wristband to be casually or mistakenly carved onto any wrist; the fact that a relief from Sennacherib's palace shows an instrument wearing this decoration suggests that the horizontal forearm harp is royal in some fashion, either as an instrument that was played specifically for the king - and he appears in the audience in all of these representations-or as an instrument that represents the king in some way.

The orientation of the hand is not constant in relation to the instrument. On all of the images of the instrument where the musician faces left in profile, the finial hand is facing the musician. In other words, the little finger (the "fifth digit" in medical terms), the leading edge of a raised hand, is closer to the musician than the thumb in these depictions, as it would be if a real person raising their hand were facing the musician. In the one instance where the musician faces right in profile (Fig. 9), the hand faces away from the musician (that is, the thumb is closer to him) ${ }^{25}$ In all cases the hand is facing to the right for anyone looking at the relief. The post is not an element you would expect to rotate on an actual instrument; as pictured, it must provide steady tension for the strings of the harp. I believe the reason for the inconsistency in orientation is best explained as the product of a different sort of consistency in representation.

Assuming that every depiction presents the viewer with the same side (back or palm) of the hand, they represent either the back of the right hand or the palm of the left. On the finials themselves there are no details to suggest either a lined palm or knuckled back of the hand. ${ }^{26}$ Without any physical details suggesting one over the other, I would suggest reading the image as the back of a right hand. The right hand side is favored in Assyrian culture and it would make sense, if one were to depict only one hand, that the dexterous, rather than sinister, hand be shown. ${ }^{27}$

\footnotetext{
${ }^{23}$ In all nine depictions of the instrument, the king is explicitly shown as part of the scene. He appears, for example, below a band of inscription but in the same scene as the musicians with decapitated heads (Fig. 3) and ahead of the musicians in the procession depicted in Figure 8. In Figure 7, two harpists face towards a slab in Sennacherib's palace that was too damaged to be drawn, but was described by Layard as having an image of the king in his chariot (Barnett, Bleibtreu and Turner 1998: 55).

${ }^{24}$ E.g. BM 124557; BM 124561 (illustrated in Curtis and Reade 1995: 45, 57). For more on the bracelet, see
}

Maxwell-Hyslop 1971: 246-49. An actual gold and inlaid bracelet of this design was among the jewellery found in the queens' tombs at Nimrud (see Harrington 1990).

${ }^{25}$ This reversal of the hand may be related to the greater reversal in the overall layout of the scene. Watanabe (1992) demonstrates how this slab differs from previous libation scenes. For another analysis of the same scene, see Atac 2006

${ }^{26}$ The reader is again reminded that details may have been painted on these sculptures and subsequently lost over time.

${ }^{27}$ See Guinan 1996. 
But why is the finial shaped like a right hand? Whose right hand is it? These questions are demonstrably significant, since this finial is the most obvious difference between the Assyrian horizontal harp and the contemporaneous Elamite horizontal harp. If the hand is there to make a gesture of some sort, then the hand's owner must have a reason for making that gesture. An open right hand held in front of the face is a cultic gesture familiar in Mesopotamia from the votive tablet of Gudea (c. 2200 B.C.), through the Code of Hammurabi (1792-1758 B.C.) and the altar of the Middle Assyrian king Tukulti-Ninurta I (1243-1207 B.C.). ${ }^{28}$ The posture is taken by a lower ranking individual (sometimes a ruler) when approaching a higher ranking individual (such as a god). ${ }^{29}$ The harp is decorated so as to represent this gesture, but performed by and for whom?

Let us presume the limb is a substitute for the arm of one of the participants at a musical performance: the musician or an audience member. If the arm is that of the musician, it may be read as performing this gesture for the musician whose hands are otherwise occupied. If the horizontal forearm harp player was engaged in approaching kings and/or divine symbols that demand respect, then the hand attached to his instrument could be one way to satisfy protocol. However, if the hand faces toward the musician, it is in a position that would be impossible to imitate with the musician's actual hand. (An argument could be made that in the absence of other iconographic markers, a contour drawing of a hand might have been assumed to show the back of a hand. Therefore, it was more agreeable to show a right hand facing the wrong direction on the instrument than it was to show a left hand facing the proper direction.) Arguing strongly against identifying the hand with the musician is the procession from Sennacherib's palace (Fig. 8) where the instruments wear rosette wristbands but the musicians themselves do not.

Another possible "musician" is the instrument itself, personified or even deified. The name of the kettledrum, lilissu, is sometimes written with the divine determinative and as early as Neo-Sumerian times, a type of harp, the balag, was accorded the same honor. ${ }^{30}$ If the finial hand is a physical element of a divine instrument, then the rosette wristband would be as appropriate there as on the apotropaic genii figures who flank the king. Similarly, the hand could belong to an archetypal early musician, possibly of divine origin. ${ }^{31}$ These speculations are intriguing but there is little evidence to either support or contradict them.

The hand might belong to an audience member, present or with the hand as proxy. If the rosette is really a royal emblem, perhaps this forearm is the gesture of a royal audience in acknowledgment of the music. It would be wholly inappropriate for the king to gesture in such a way towards the musician; however, it is within the realm of possibility that the royal gesture was directed towards the very music emanating from the instrument. Statues and icons of deities were not merely symbols of the gods in Mesopotamia, but manifestations of the divine. ${ }^{32}$ Could a sound-music, in this case - be similarly regarded as an embodiment of a god? Such a concept is not unheard of. In Islam, the sacred word of the Prophet, as recorded in the Koran, is a received (and then subsequently ritualized) aural transmission. ${ }^{33}$ Given Islam's example, we should acknowledge at least the possibility that the sound emanating from the Neo-Assyrian instrument may have been conceived as worthy of respect or worship. ${ }^{34}$

${ }^{28}$ These are illustrated in Moortgat 1969 (pls. 185, 209 and 246 , respectively).

${ }^{29}$ This gesture of greeting or blessing is called kara $\bar{b} u$; apotropaic figures on the palace reliefs also make this gesture towards stylized representations of palm trees (Russell 1998: 675).

${ }^{30}$ The divine determinative is used in the Ur III period, CAD "B": 39, balaggu, 1b: TCL 55672 i 15, also iii 11 . I do not believe the horizontal forearm harp is a balag however, because of the late introduction of the instrument. If the Mesopotamians had categories of instrument like ours, "harp" with various types therein, then it would be possible that the Neo-Assyrian instrument was a "sort" of balag. My thanks to Andrew $C$. Cohen for pointing this out and suggesting this interpretation.
${ }^{31}$ I am grateful to an anonymous reader for this suggestion. ${ }^{32}$ See Winter 1992.

${ }^{33}$ The name of the book itself, " $a l-Q u r ' a n$ ", means "The Recitation" referring to the original divine word received by Muhammad but also to its use as a text that is meant to be spoken and heard (Graham 1985: 30; see also the discussion of oral tradition in Sells 1999).

${ }^{34}$ In my dissertation, I discussed the words used to describe music in Mesopotamia and found that music was admired for its purity, emotional resonance and physical effects on the audience (both positive and negative) (Cheng 2001: 155-66). These characteristics give a hint of the Assyrian attitude toward music, an attitude that could conceivably support the concept of music as a divine power. 
A further possibility is that the hand belongs to a divine audience member. In that case, there are several potential readings. The gesture could be a blessing, maybe conferring skill to the player. Or, it could be a divine limb imparting a blessing on the music or on the audience at the performance. Or, the music may have been thought to flow from the hand of a god. Too little is understood about Neo-Assyrian cult practice to do more than list some possibilities here.

Textual clues are frustratingly difficult to interpret. The Akkadian word for arm is $i d u$ and for the right hand, imittu. ${ }^{35}$ No references or expressions involving these words can be applied to further explain the decoration and use of this instrument, although it is the favored right hand that bestows blessings in texts as well as images. ${ }^{36}$ There is a term, tarāsu, "to stretch out/toward," said of the finger (ubānu), hand ( $q \bar{a} t u$ ) and arm, whose contexts imply a gesture of blessing, curse or apotropaic significance. ${ }^{37}$ There are two lexical texts that associate the arm or hand with instruments. The first is a sequence of lines that seems to associate the sammû instrument with the hand. ${ }^{38}$ Another lexical text, nabnitu 32, mentions the "arm" of the algar instrument. ${ }^{39}$.Unfortunately, the meaning of both sammî and algar is uncertain, and both texts may have origins earlier than the Neo-Assyrian period. ${ }^{40}$

Whatever the deeper iconographical implications of the hand on the instrument, one fact can be established. Based on the decorative rosette wristband and the royal audience of the forearm harp, usually at official ceremonies like libations or processions, we should consider the harp a highlevel, even "royal" instrument. ${ }^{41}$ At this point in history, it is difficult to separate the cult of Ashur from the State of Assyria, or either from the person of the king himself. Ann Shafer, in a discussion of a scene of Shalmaneser III dedicating a statue depicted on the Balawat bronze gates (similar to Fig. 6) writes:

There in his role as chief priest of Ashur, the Assyrian king sanctifies Assyria's new border, which, as is emphasized by the careful rendering of the mountainous landscape below, is very literally carved from the land itself. In the process of virtually acknowledging his own image-as-border, the king foregrounds the crucial role of his own divinely sanctioned deeds and accomplishments. ${ }^{42}$

At this moment, Shalmaneser III stands in person as a priest, king and military leader and his image represents all of those roles as well as the very border of Assyria itself. ${ }^{43}$ Viewed through this prism of regal duties, the horizontal forearm harp is perhaps best seen as royal not in the more limited sense of having a royal audience, ${ }^{44}$ but in the grander scheme of state and cult - -and even geography. I do not mean to imply that the harp may represent the king himself, but rather I am making the claim that the harp may evoke the same ideas that representations of the king do, of Assyria and Ashur. This would explain the instrument's use in both military and religious scenes, either in scenes located toward the edge of recognizably Assyrian territory or at the physical center of the Assyrian administration.

In effect, I am suggesting that the horizontal forearm harp may well have been the national instrument of the Neo-Assyrian state. By this I mean that the instrument itself was associated with Assyria and Assyrian culture at the highest levels, and I would not exclude the possibility that the forearm harp was used to play recognizably Neo-Assyrian music, although this must remain mere speculation.

${ }^{35}$ CAD "I J": idu, 10-20, CAD "I-J": imittu, 120-23. Another word, kabittu, can be used as a euphemism to refer to the left hand, $C A D$ " $\mathrm{K} ":$ kabittu, 21. I thank Glenn Magid for referring me to the proper Akkadian terms.

${ }^{36}$ On blessings in images, see among others the bronze "Great Amulet" of Lamaštu, where the sick patient, as well as two men in fish costumes gesture upwards with their hands, see Matoušová-Rajmová 1989. On blessings in texts, see $C A D$ "I-J": imittu, 122, "he has human hands, with his right hand he makes the gesture of blessing" MIO $178 \mathrm{v} 44$. A Standard Babylonian description of a representation of a demon.

${ }^{37}$ See $A H w$, tarăṣu, 1326-27.
${ }^{38}$ Lawergren and Gurney 1987: 48-49.

${ }^{39}$ MSL $16,32,1.11$, p. 252.

40 Lawergren and Gurney 1987: 48-49.

41 Ann Kilmer writes: "It is of interest to note that one NA text (BM ANE 65217+) relating to technical music terms concerns ikribu-prayers anašarrim 'for the king"" (Kilmer 1984; see also Reiner 1991).

42 Shafer 1998: 96.

${ }^{43}$ The notion of multiple kings, and the multitude of meanings that spring from them, is developed in Kantorowicz 1957, and further elaborated by Marin 1988.

${ }^{44}$ It is not present, for example, in the best known scene of a king enjoying music: Ashurbanipal's Banquet scene. 


\section{Conclusions}

In sum, the instrument under discussion is decorated with a forearm that has been shown to wear the rosette wristband associated with the king. It is played only by Assyrian men, the most empowered citizens of the state. The harp is shown to be played at religious and military events at which the king is present and might have been expected to have directed events. The horizontal forearm harp would therefore have acted as a symbol for the Assyrian state much in the same way as the image of the king himself. For all of these reasons, I would suggest that the decorative forearm on the instrument should be interpreted as a proxy arm of the king, sharing some of the multiple duties assigned to him.

Assuming the horizontal forearm harp had associations of royalty, divinity, and nationhood, how would these associations affect how we read the reliefs? It would be possible to argue for either religion or politics to be the overriding theme- that is, all military scenes represent the conquest of the god Ashur, or all religious scenes represent the advancement of the Assyrian state through the national cult - and thus neither is satisfactory. However, we should probably consider the religious scenes more political than previously thought and vice versa. With the horizontal forearm harps in attendance, for example, the scenes of Assurnasirpal II and Assurbanipal pouring libations over the dead animals they have just hunted should perhaps be seen not only in cultic terms, but also as a nation-building, political event. Elnathan Weissert makes a similar argument using textual evidence, pointing out that in texts as well as images, the hunt and libation parallel military victories and libation. ${ }^{45}$ In contrast, a military scene like the one amid the remains of a battle, where soldiers bring the decapitated heads of enemy soldiers to harpists, should perhaps not be considered wholly secular (Fig. 3). Although the cult of Ashur was apparently not evangelical, ${ }^{46}$ perhaps the horizontal forearm harps were brought on campaign for pre-battle invocations or, after the battle, to consecrate new markers of the Assyrian border (as depicted on the Balawat Gates, Fig. 6).

Perhaps the most wide-ranging symbolic use of the horizontal forearm harp is in the Assyrian processions depicted on the Balawat Gates of Assurnasirpal II (Fig. 5). I imagine that similar ensembles played for other Assyrian kings like Esarhaddon, who described his return to the capital in this way:

That the might of Assur, my lord, might be made manifest, I hung their heads upon the shoulders of their nobles and with singing and music I paraded through the public square of Nineveh. ${ }^{47}$

In this case, the harp, like the king, would represent multiple functions. Where the king could be seen as the priest, military leader, and personification of Ashur and Assyria, the horizontal forearm harp could conceivably be seen as representing the state cult and cult of state, the strong arm of the king, the voice of the god, the spirit of the nation, and the centre of an empire.

\section{Bibliography}

Ataç, M.-A. 2006. Visual Formula and Meaning in Neo-Assyrian Relief Sculpture. The Art Bulletin 88(1): 69-101.

Barnett, R. D. 1969. New Facts About Musical Instruments from Ur. Iraq 31(2): 96-103.

Barnett, R, D. 1976. Sculptures from the North Palace of Assurbanipal at Nineveh (668-627 B.C.). London: British Museum Press.

Barnett, R. D., Bleibtreu, E. and G. Turner. 1998. Sculptures of the Southwest Palace of Sennacherib at Nineveh. London: British Museum Press.

Cheng, J. 2001. Assyrian Music as Represented and Representations of Assyrian Music. Ph.D. dissertation, Harvard University.

Cheng, J. 2009. A Review of Early Dynastic III Music: Man's Animal Call. Journal of Near Eastern Studies 68: $163-78$.

Curtis, J. E. and J. E. Reade (eds.) 1995. Art and Empire: Treasures from Assyria in the British Museum. London: British Museum Press.

Curtis, J. E. and N. Tallis (eds.) 2008. The Balawat Gates of Ashurnasirpal II. London: British Museum Press. de Waele, E. 1989. Musicians and Musical Instruments on the Rock Reliefs in the Elamite Sanctuary of Kul-e Farah (Izeh). Iran 27: 29-38.

\footnotetext{
${ }^{45}$ Weissert 1997

${ }^{46}$ Frame 1997.
}

\footnotetext{
${ }^{47}$ Esarhaddon (Luckenbill 1926-27 vol. II: 206). "Singing and music" are translated from "amzammeri u GIŠ.ZAG. SAL."
} 
Frame, G. The God Aššur in Babylonia. In S. Parpola and R. M. Whiting (eds.), Assyria 1995: Proceedings of the 10th Anniversary Symposium of the Neo-Assyrian Text Corpus Project, Helsinki, September 7-11, 1995. Helsinki: The Neo-Assyrian Text Corpus Project. pp. 55-64.

Graham, W. A. 1985. Qur'ān as Spoken Word: An Islamic Contribution to the Understanding of Scripture. In R. C. Martin (ed.), Approaches to Islam in Religious Studies. Tucson: University of Arizona Press. pp. 23-40.

Guinan, A. K. 1996. Left/Right Symbolism in Mesopotamian Divination. State Archives of Assyria Bulletin 10(1): 5-10.

Harper, P. O., Klengel-Brandt, E., Aruz, J. and K. Benzel (eds.) 1995. Assyrian Origins: Discoveries at Ashur on the Tigris. Antiquities in the Vorderasiatisches Museum, Berlin. New York: Metropolitan Museum of Art.

Harrington, S. P. M. 1990. Royal Treasures of Nimrud. Archaeology 43 (July/August): $48-53$.

Kantorowicz, E. 1957. The King's Two Bodies: A Study in Medieval Political Theology. Princeton: Princeton University Press.

Kilmer, A. 1984. A Music Tablet from Sippar (?): BM ANE 65217+66616. Iraq 46: 69-80.

Lamprichs, R. 1995. Die Westexpansion des neuassyrischen Reiches. Eine Structuranalyse. Alter Orient und Altes Testament 239. Kevelaer/Neukircher: Butzon und Bercker/Neukirchener.

Lawergren, B. and O. R. Gurney. 1987. Sound Holes and Geometrical Figures: Clues to the Terminology of Ancient Mesopotamian Harps. Iraq 49: 37-52.

Layard, A. H. 1849. Nineveh and its Remains. 2 vols. London: John Murray.

Luckenbill, D. D. 1926. Ancient Records of Assyria and Babylonia. Chicago: Chicago University Press.

Marin, L. 1988. Portrait of the King (trans. M. M. Houle). Minneapolis: University of Minnesota Press.

Maxwell-Hyslop, K. R. 1971. Western Asiatic Jewellery, c. 3000-612 B.C. London: Methuen and Co.

Matoušová-Rajmová, M. 1989. Die Darstellung einer Krankenbeschwörung auf dem „Grossen Amulett“. Archív Orientální 57: 141-47.

Mitchell, T. C. 1980. An Assyrian Stringed Instrument. In T. C. Mitchell (ed.), Music and Civilisation. British Museum Yearbook. London: British Museum Publications. pp. 33-42.

Moortgat, A. 1969. The Art of Ancient Mesopotamia. New York: Phaidon.

Parrot, A. 1961. Assur. Paris: Gallimard.

Rashid, S. A. 1984. Mesopotamien. Musikgeschichte in Bildern II, 2. Leipzig: Deutscher Verlag für Musik.

Reiner, E. 1991. Quelques voeux. In D. Charpin and F. Joannès (eds.), Marchands, diplomates et empereurs: Études sur la civilisation mésopotamienne offertes à Paul Garelli. Paris: Éditions Recherches sur les Civilizations. pp. 421-22.

Rimmer, J. 1969. Ancient Musical Instruments of Western Asia. London: British Museum Press.

Russell, J. M. 1998. The Program of the Palace of Assurnasirpal II at Nimrud: issues in the research and presentation of Assyrian art. American Journal of Archaeology 102: 655-715.

Sells, M. 1999. Approaching the Qur'an: The Early Revelations. Ashland, OR: White Cloud.

Shafer, A. T. 1998. The Carving of an Empire: Neo-Assyrian Monuments on the Periphery. Ph.D. dissertation, Harvard University.

Tadmor, H. 1975. Assyria and the West: The Ninth Century and its Aftermath. In H. Goedicke and J. J. M. Roberts (eds.), Unity and Diversity: Essays in the History, Literature and Religion of the Ancient Near East. Baltimore: Johns Hopkins University Press. pp. 3648.

Watanabe, C. 1992. A Problem with the Libation Scene of Assurbanipal. In T. Mikasa (ed.), Cult and Ritual in the Ancient Near East. Wiesbaden: Harrasowitz. pp. 91-104.

Winter, I. J. 1982. Art as Evidence of Interaction: Relations between the Assyrian Empire and North Syria. In H.-J. Nissen and J. Renger (eds.), Mesopotamien und seine Nachbarn. Berliner Beiträge zum Vorderen Orient. Berlin: Dietrich Reimer Verlag. pp. 355-82, pls. xlix-lix.

Winter, I. J. 1992. "Idols of the King": Royal Images as Recipients of Ritual Action in Ancient Mesopotamia. Journal of Ritual Studies 6(1): 13-42.

Weissert, E. 1997. Royal Hunt and Royal Triumph in a Prism Fragment of Assurbanipal (82-5-22, 2). In S. Parpola and R. M. Whiting (eds.), Assyria 1995: Proceedings of the 10th Anniversary Symposium of the Neo-Assyrian Text Corpus Project, Helsinki, September 7-11, 1995. Helsinki: The NeoAssyrian Text Corpus Project. pp. 339-58.

Jack Cheng

165 Paulson Road

Waban, MA 02468

USA

jack.cheng@gmail.com

jackcheng@post.harvard.edu 